\title{
Interaction of replication factor Sld3 and histone acetyl transferase Esa1 alleviates gene silencing and promotes the activation of late and dormant replication origins
}

\author{
Seiji Tanaka* \\ School of Environmental Science and Engineering, Kochi University of Technology, 185 Miyanokuchi, Tosayamada, Kami, Kochi 782-8502, Japan \\ *Address for correspondence: School of Environmental Science and Engineering, Kochi University of Technology, 185 Miyanokuchi, Tosayamada, Kami, Kochi 782- \\ 8502, Japan. tanaka.seiji@kochi-tech.ac.jp
}

\begin{abstract}
DNA replication in eukaryotes is a multi-step process that consists of three main reactions: helicase loading (licensing), helicase activation (firing), and nascent DNA synthesis (elongation). Although the contributions of some chromatin regulatory factors in the licensing and elongation reaction have been determined, their functions in the firing reaction remain elusive. In the budding yeast Saccharomyces cerevisiae, Sld3, Sld7, and Cdc45 (3-7-45) are rate-limiting in the firing reaction and simultaneous overexpression of 3-745 causes untimely activation of late and dormant replication origins. Here, we found that 3-7-45 overexpression not only activated dormant origins in the silenced locus, $H M L \alpha$, but also exerted an anti-silencing effect at this locus. For these, interaction between Sld3 and Esa1, a conserved histone acetyltransferase, was responsible. Moreover, the Sld3-Esa1 interaction was required for the untimely activation of late origins. These results reveal the Sld3-Esa1 interaction as a novel level of regulation in the firing reaction.
\end{abstract}

Keywords: DNA replication; Sld3; Esa1; silencing; origin firing

\section{Introduction}

In eukaryotes, DNA is stored in the nucleus as specific proteinnucleic acid complexes called chromosomes. Each chromosome is made up of basic units called nucleosomes, each of which contains DNA and a histone octamer. The properties of the nucleosomes are regulated by the posttranslational modification of histones. Differences in these modifications generate local chromatin structure, which in turn affects transcription capacity and the efficiency of DNA repair. However, the effects of chromatin on DNA replication are not well understood.

Eukaryotic DNA replication initiates from multiple specific regions of chromosomes, called replication origins. DNA replication is a complex but well-organized multi-step process. In the first reaction, called licensing or pre-replicative complex (pre-RC) assembly, the core of the replicative helicase, the Mcm2-7 complex, is loaded onto replication origins as an inactive double hexamer (Evrin et al. 2009; Remus et al. 2009; Ticau et al. 2015, 2017; Coster and Diffley 2017; Miller et al. 2019). Next, two essential protein kinases, Dbf4-dependent kinase (DDK), CDK-dependent kinase (CDK), and $\mathrm{Mcm} 10$, promote activation of the replicative helicase (Tanaka et al. 2007, 2011; Zegerman and Diffley 2007; Muramatsu et al. 2010; Heller et al. 2011; Kanke et al. 2012; van Deursen et al. 2012; Watase et al. 2012; Tanaka and Araki 2013; Deegan et al. 2016; Looke et al. 2017; Miyazawa-Onami et al. 2017; Douglas et al. 2018). In this reaction, called firing, the inactive Mcm2-7 double hexamer is converted into an active helicase, the CMG (Cdc45-Mcm2-7-GINS) complex. Finally, the active replication fork is assembled, and nascent DNA is synthesized (elongation).

Chromatin structure is proposed to influence these steps of DNA replication. For example, in mammalian cells, chromatin regulatory factors such as Hbo1, Snf2, GRWD1, and PR-Set7 play roles in promoting licensing (Chadha and Blow 2010; Sugimoto et al. 2011, 2015; Aizawa et al. 2016; Brustel et al. 2017). They may act by helping to exclude nucleosomes from future Mcm2-7loading sites, as chromatin-loaded Mcm2-7 double hexamers and nucleosomes occupy their positions on chromatin in a mutually exclusive manner (Berbenetz et al. 2010; Eaton et al. 2010). During the elongation reaction, nucleosomes in front of the replication fork must be removed, and then they re-assemble after fork passage. For example, FACT (facilitates chromatin transcription), INO8IEW1a, Gcn5, and Esa1 are known to play an important role in the elongation step both in vivo and in vitro (Tan et al. 2006; Foltman et al. 2013; Devbhandari et al. 2017; Kurat et al. 2017). By contrast, the role of chromatin regulatory factors in the firing reaction remains elusive.

Because eukaryotic cells have multiple replication origins, each with their own timing for activation, the firing reaction occurs throughout the S-phase of the cell cycle (reviewed in Rhind and Gilbert 2013), i.e., some origins fire early in S-phase, some fire late, and some do not fire if the replication fork passes 
through them before firing occurs; the last category of origins is considered "dormant". In a previous study, we showed that Sld3, Sld7, and Cdc45 are loaded onto the pre-RC in a DDK-dependent manner as the first step of firing. Because these factors are much less abundant than replication origins, they are limiting for firing; accordingly, in the budding yeast Saccharomyces cerevisiae, simultaneous overexpression of Sld3-Sld7-Cdc45 (3-7-45) affects the firing pattern of origin activation (Tanaka et al. 2011). We observed that untimely activation of dormant origins in the silenced locus HML $\alpha$ occurred under the overexpression of 3-7-45. Here, we show that 3-7-45 overexpression also affects the silencing of HML $\alpha$. These effects depend on the interaction of Sld3 and Esa1, the catalytic subunit of the histone acetyltransferase complex NuA4, which is also called Kat5 (K-acetyl transferase 5). Our data reveal a novel level of firing regulation mediated by the interaction between the firing factor Sld3 and the chromatin regulator Esa1.

\section{Materials and Methods Yeast strains and media}

S. cerevisiae strains are listed in Supplementary Table S1. Cells were grown in the rich medium YPA (1\% yeast extract, $2 \%$ Bacto peptone, $40 \mathrm{mg} / \mathrm{L}$ adenine) supplemented with $2 \%$ sugar (glucose, galactose, or raffinose), or in synthetic medium containing $0.67 \%$ yeast nitrogen base without amino acids (\# 291940; Difco Laboratories, Detroit, MI, USA) and 2\% glucose, supplemented with the appropriate amino acids and drugs. Cell-cycle block and release experiments with $\boldsymbol{\alpha}$-factor were performed as described previously (Tanaka et al. 2011; Miyazawa-Onami et al. 2017). All strains used in this analysis are available from the National Bio Resource Project (NBRP) yeast (http://yeast.nig.ac.jp/yeast/top.xhtml).

\section{Screening of chromatin regulatory factors interact with Sld3, Sld7, and Cdc45}

To identify chromatin regulatory factors that interact with Sld3, Sld7, and Cdc45, we cloned 26 genes that were listed by the keyword "histone acetyltransferase" in the Saccharomyces Genome Database web site (https://www.yeastgenome.org/). Each of them were cloned into the vectors for the yeast two-hybrid (Y2H) assay, DNA-binding domain (DB) vector pST1667 and the activation domain (AD) vector pST548 (Tanaka 2019), respectively, and their capability of interaction with any of Sld3, Sld7, and Cdc45 was tested by the Y2H color assay (Bartel and Fields 1995).

\section{Isolation of mutants with diminished interactions between Sld3 and Esa1}

To construct the mutant library, SLD3 and ESA1 ORF were PCRamplified with Taq polymerase (MightyAmp ver. 2; Takara Bio Co., Otsu, Japan) and cloned into the BamHI sites of the Y2H DB vector pST1667 and the Y2H AD vector pST548 (Tanaka 2019), respectively, using the In-Fusion enzyme (Takara Bio Co,). Mutant libraries of DB-Sld3 and AD-Esa1 were introduced into the $\mathrm{Y} 2 \mathrm{H}$ host TAT-7 strain harboring AD-Esa1 and DB-Sld3, respectively. After 1 day of incubation, the original plates were replicated, and the incubation was continued. After colony formation, cells were lifted from the replicated plates and subjected to the Y2H color assay (Bartel and Fields 1995). "White" candidates were picked from the original plate and re-streaked for confirmation of the white phenotype. In parallel, whole-cell extracts were prepared from the re-streak and analyzed by western blotting. Candidates generating full-length or near-full-length protein were stored as secondary candidates. Plasmids were recovered from secondary candidates, and the white phenotype in the $\mathrm{Y} 2 \mathrm{H}$ color assay was confirmed (tertiary candidates). From tertiary candidates, clones with endogenous promoters were constructed in YCp-type plasmids and clones that could support cell growth were selected by plasmid shuffling; the resultant mutants were denoted $\operatorname{sld} 3^{\text {Esa1(-) }}$ and esa1 ${ }^{\text {Sld3(-) }}$

\section{Construction of yeast strains}

When a plasmid such as GALp-3/4/75 was integrated into yeast genome, integrated copy number of the plasmid was confirmed by monitoring the change in the length of targeted region by Southern blotting. To construct the strain harboring the sld $3^{\text {Esa1 (-) }}-3$ or esa $1^{\text {Sld } 3(-)}-2$ allele as the sole copy of the respective genes, the gene replacement method using URA3/5-FOA selection called the "pop-in/pop-out" method (Boeke et al. 1987) was employed. The alleles in the SLD3 or ESA1 locus of the resultant clone were confirmed by DNA sequencing

\section{Other methods}

Flow cytometry was performed as described (Tanaka and Diffley 2002b). Replication intermediates were detected using alkaline gels as described (Tanaka et al. 2011). Preparation of yeast wholecell extracts and western blotting were performed as described (Tanaka et al. 2011). Y2H assay was performed as described (Tanaka et al. 2013). The plasmid loss rate was measured as described (Tanaka and Diffley 2002a).

\section{Data availability statement}

Strains and plasmids are available upon request. The authors affirm that all data necessary for confirming the conclusions of the article are present within the article, figures, and tables.

Supplementary material is available at figshare DOI: 10.25386/ genetics.13172369.

\section{Results \\ Simultaneous expression of Sld3-Sld7-Cdc45 counteracts $\mathrm{HML} \alpha$ silencing}

In a previous analysis, we showed that the simultaneous overexpression of Sld3, Sld7, and Cdc45 (3-7-45 expression) promotes early firing of many origins, including late and dormant origins (Tanaka et al. 2011). We also observed activation of dormant origins located in and near the silenced locus HML $\alpha$, such as ARS301, ARS302, ARS303, and ARS320 (Vujcic et al. 1999) (Supplementary Figure S1, A and B). Therefore, we asked whether the expression of 3-7-45 also affects the silencing status of HML $\alpha$. To address this question, we used a strain in which wild-type URA3 is inserted into HML $\alpha$ (hml $\alpha:$ URA3) (Singer and Gottschling 1994) (Figure 1, A and B). Due to this URA3 insertion, the silencing status of HML $\alpha$ can be easily monitored: when HML $\alpha$ is silenced, cells are $\mathrm{Ura}^{-}$and 5-FOA resistant (Figure 1C, top row: $h m l \alpha:: U R A 3)$; conversely, when silencing is lost, as in a sir mutant, cells are $\mathrm{Ura}^{+}$and 5-FOA sensitive (Figure 1C, bottom two rows: $\Delta$ sir1 and $\Delta$ sir2). As previously reported, $\Delta$ sir2 showed stronger phenotype than $\Delta$ sir1 because of the difference of the roles in the HML $\alpha$ silencing (Ivy et al. 1986; Pillus and Rine 1989; Gross 2001; Pillus and Rine 2004), which indicates that this assay is effective to test the extent of HML $\alpha$ silencing. When 3-7-45 was overexpressed, cells exhibited an intermediate phenotype: they grew better than vector control on SC-Ura, and growth was weakly inhibited on 5-FOA (Figure 1D, third and fourth rows: shown as "+ GALp-3-7-45"). Interestingly, the strength of the "antisilencing" effect caused by the 3-7-45 expression increased with the integrated copy number of the GALp-3-7-45 plasmid 
A

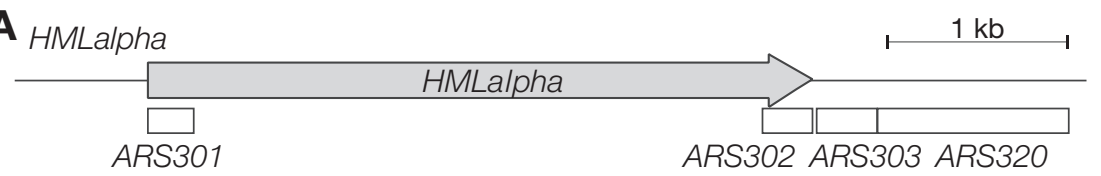

B hmlalpha::URA3

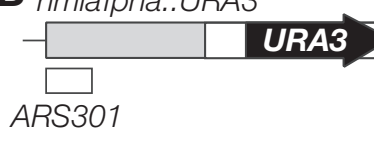

C

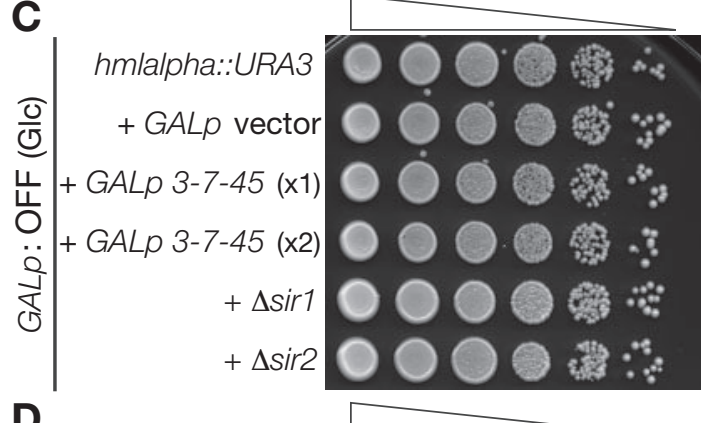

D

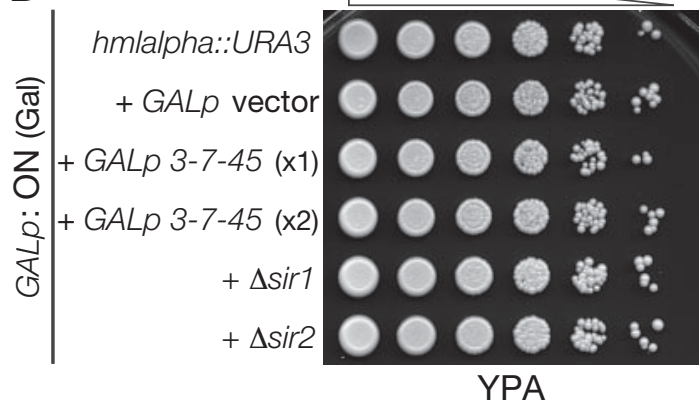

ARS302 ARS303 ARS320
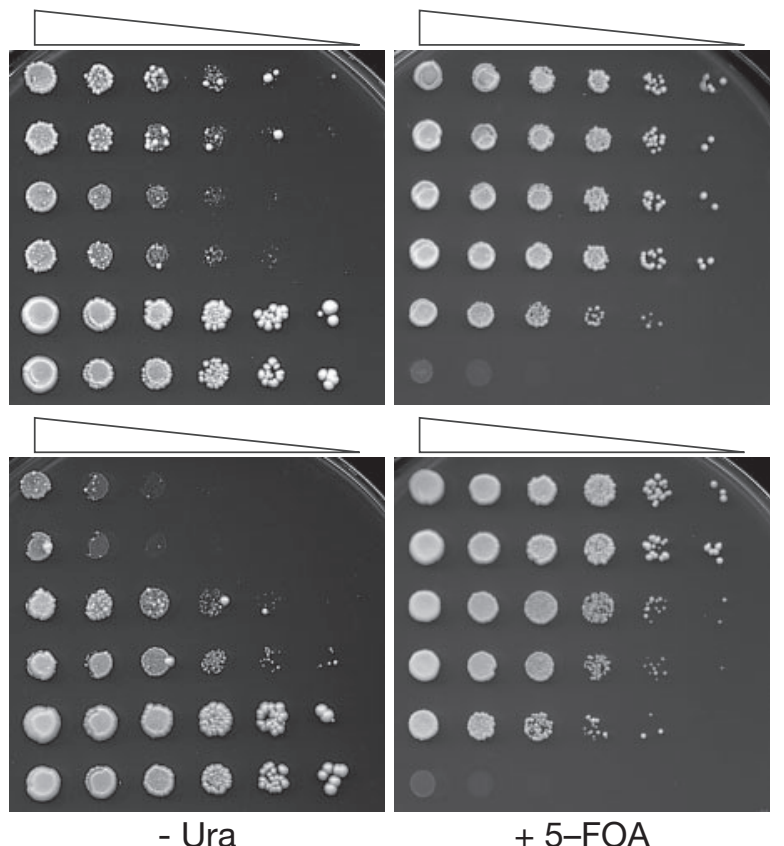

Figure 1. Expression of 3-7-45 induces an anti-silencing effect at HML $\alpha$. (A) Schematic representation of the HML $\alpha$, ARS301, ARS302, ARS303, and ARS320. Positions of each element are based on those in the Saccharomyces Genome Database (https://www.yeastgenome.org). (B) Schematic representation of the HML $\alpha:$ URA3 construct. (C, D) HML $\alpha:$ URA3 cells (UCC3515) and HML $\alpha:$ URA3 cells harboring the GALp vector (YST1788), 1 or 2 copies of GALp-3-7-45 (shown as $\times 1$ and $\times 2$, respectively: YST1789 and YST1790), and $\Delta$ sir1 and $\Delta$ sir2 cells (YST1861 and YST1862) were serially diluted, spotted on the indicated plates, and grown at $30^{\circ} \mathrm{C}$ for 2 days (all glucose plates), 3 days [YPAGal and SC +5 -FOA (Gal) plates] or 4 days [SC-Ura (Gal) plate].

(Figure 1C, third and fourth rows: the numbers of integrated copies of the plasmid are shown in parentheses as " $\times 1$ " and " $\times 2$ ", respectively), suggesting that $3-7-45$ is directly involved in this phenomenon. Together, these observations indicate that the expression of 3-7-45 exerts an anti-silencing effect and that the strength of this effect is related to the expression levels of 3-7-45.

\section{Anti-silencing effects depend on the replication function of 3-7-45}

The Sld3-Sld7-Cdc45 complex functions in origin firing; specifically, it associates with the Mcm2-7 complex at the licensed origin in a DDK-dependent manner during the firing reaction (Heller et al. 2011; Tanaka et al. 2011). In a previous study, we observed that untimely activation of origins caused by 3-7-45 expression required the expression of all three genes; expression of any one or two of them did not induce untimely origin firing except in the case of simultaneous expression of Sld3 and Sld7, which triggered very weak activation of origins (Tanaka et al. 2011). The antisilencing effect caused by 3-7-45 expression recapitulated this, i.e., the anti-silencing effect was observed only when all three genes were expressed; a very weak anti-silencing effect was observed when Sld3 and Sld7 were simultaneously expressed (Supplementary Figure S1C).
If the anti-silencing effect caused by 3-7-45 expression depends on its replication-related function, which involves the association of 3-7-45 with the DDK-phosphorylated Mcm2-7 complex at licensed origins, then the anti-silencing effect must depend on origin licensing. Replication origins are licensed from the end of M-phase until they are activated in S-phase. Therefore, if the duration of time when cells harbor licensed origins is changed, it would affect the anti-silencing effect of 3-7-45. To test this possibility, we used the $\Delta$ swe1 and $\Delta$ mih1 mutants. Because Swe1 and Mih1 regulate the timing of onset of M-phase via activation of $\mathrm{M}$-phase CDK in opposite manners, and M-phase entry is accelerated in $\Delta$ swe1 and delayed in $\Delta$ mih1, the length of G1 phase is longer in $\Delta$ swe1 than in the wild type, and shorter in $\Delta$ mih1 (Russell et al. 1989; Booher et al. 1993). The anti-silencing effect of 3-7-45 was strengthened in $\Delta$ swe1 cells and weakened in $\Delta$ mih1 cells (Supplementary Figure S1D). On the basis of these observations, we concluded that the anti-silencing effect is a result of the origin association of 3-7-45.

\section{Sld3 interacts with Esa1}

The chromatin regulatory functions of 3-7-45 remain unknown. To begin to investigate this issue, we postulated that any of Sld3, Sld7, and Cdc45 interacts with chromatin regulatory factors. 
To identify such interactors, we performed systematic Y2H assays and found that Sld3 interacts with Esa1, the budding yeast ortholog of lysine acetyl transferase 5 (Kat5) and the catalytic subunit of NuA4 histone acetyl transferase (HAT) (Figure 2A and Supplementary Figure S2A) (Clarke et al. 1999). Esa1 also exhibited a weak interaction with Sld7 but did not interact with Cdc45 in this assay.

\section{NuA4 subunits interact genetically with Sld3}

NuA4 HAT consists of 13 subunits including Esa1 (Allard et al. 1999). Although Esa1 is essential for cell growth, some subunits of NuA4 are not. To elucidate the functional relationship between Sld3 and NuA4, we deleted several of the non-essential subunits of NuA4, $\Delta$ eaf3, $\Delta$ eaf5, $\Delta$ eaf6, $\Delta$ eaf7, and $\Delta$ yaf9 in cells harboring temperaturesensitive alleles of SLD3, sld3-5, and sld3-6 (Kamimura et al. 2001). Some of the mutant alleles exhibited a genetic interaction

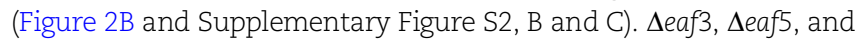
$\Delta$ eaf6 exacerbated the sensitivity of the sld3-6 mutant to high temperature and HU (Figure 2B). By contrast, $\Delta$ eaf7 and $\Delta y$ af9 exhibited an opposite effect in the same background (Figure 2B and Supplementary Figure S2B). No such effect was observed in another sld3-ts allele, sld3-5 (Supplementary Figure S2C). All of the deletion
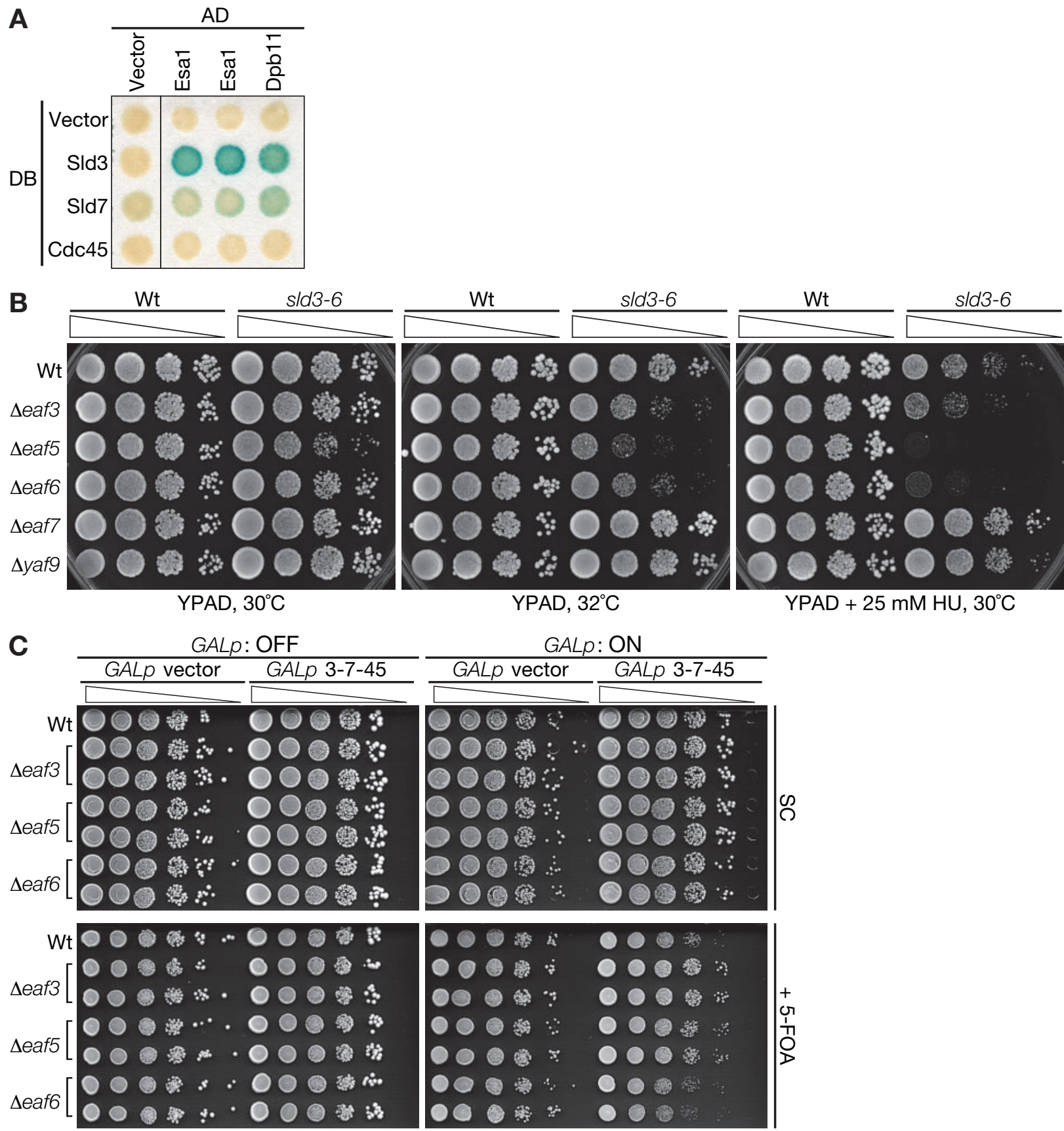

Figure 2. Sld3 interacts with Esa1. (A) Y2H analysis was performed with plasmids encoding the indicated proteins. (B) $\Delta$ eaf3, $\Delta$ eaf5, $\Delta$ eaf6, $\Delta$ eaf7, and syaf9 cells in the wild type (Wt) or sld3-6 background were spotted and grown under the indicated conditions. Strains used were W303-1a $\Delta$ bar1, YST2327, YST2329, YST2330, YST2331, and YST2551 (Wt background, from top) and YYK16, YST3406, YST2313, YST2314, YST3407, and YST3408 (sld3-6 background, from top). (C) HML $\alpha:$ :URA3-harboring Wt, $\Delta$ eaf3, $\Delta$ eaf5, and $\Delta$ eaf6 cells harboring the GALp vector or GALp-3-7-45 were spotted and grown under the indicated conditions. Strains used were YST1788, YST2345, YST2346, and YST2347 (GALp vector, from top) and YST1790, YST2351, YST2352, and YST2353 (GALp-3-7-45, from top). 
mutants weakly exacerbated the phenotype of sld3-5. This difference between sld3-5 and sld3-6 backgrounds might be due to differences in the properties of alleles. Collectively, the results of this experiment revealed a genetic interaction between NuA4 and SLD3.

Based on the existence of a genetic interaction between Sld3 and NuA4 subunits, we next asked whether $\Delta$ eaf3, $\Delta$ eaf5, and $\Delta$ eaf6 affect the anti-silencing effect of 3-7-45 in the HML $\alpha:$ URA3 cells, as these three deletions exhibited similar synthetic effects in both sld3-5 and sld3-6 backgrounds. Although $\Delta$ eaf6 had no obvious effects, $\Delta$ eaf3 and $\Delta$ eaf5 weakened the anti-silencing effect (Figure 2C). This indicates that NuA4 somehow contributes to the anti-silencing caused by $3-7-45$ expression.

\section{Deletion of the NuA4 subunit Eaf5 affects the activity of origins in the silenced locus HML $\alpha$}

To further elucidate the genetic interactions between Sld3 and NuA4 subunits, we asked whether NuA4 has an effect on the activities of dormant origins located in the silenced locus HML $\alpha$. To answer this question, we performed a plasmid loss assay with centromeric plasmids harboring the early replication origin ARS1, a short fragment derived from HML $\alpha$ that only contains ARS301, or the whole region of HML $\alpha$ plus ARS302-320 (hereafter denoted as ARS1, ARS301, and ARS301-320; for details, see Supplementary Figure S3, A and B). The ARS301-containing short fragment has characteristics of a late replication origin even in a plasmid context (Santocanale and Diffley 1996; Bousset and Diffley 1998), probably due to its chromatin structure. Therefore, we first investigated whether the HML $\boldsymbol{\alpha}$-derived fragments were silenced on the plasmid. The URA3 reporter gene, which was inserted proximal to or between the HML $\alpha$-derived origins, was silenced in the ARS301 and ARS301320 plasmids, but not in the ARS1 plasmid (Supplementary Figure S3C). We concluded that HML $\alpha$-derived fragments are silenced in the plasmid context, as in the chromosome context.

ARS301 and ARS301-320 plasmids were lost at higher rates than the ARS1 plasmid (Figure 3A), suggesting poorer DNA replication of these origins. Importantly, this high plasmid loss rate was suppressed by the deletion of SIR2, which encodes silencing factor (Rine and Herskowitz 1987), $\Delta$ sir2 (Figure 3A), implying that the higher loss rate of ARS301 and ARS301-320 plasmids was related to silencing. Deletion of the NuA4 subunit Eaf5 increased the loss rate of ARS301 and ARS301-320 plasmids, but not that of the ARS1 plasmid (Figure 3A), indicating that the deletion interfered with the replication of these plasmids. Conversely, 3-7-45 expression suppressed the high loss rate of ARS301 and ARS301-320 plasmids (Figure 3B). Finally, the combination of $\Delta$ eaf5 and 3-7-45 expression resulted in an intermediate loss rate for the ARS301 and ARS301-320 plasmids (Figure 3C). Therefore, we concluded that the NuA4 complex, at least Eaf5, positively affects not only the anti-silencing effect of 3-7-45 but also the activation of dormant origins in HML $\alpha$.

\section{The Sld3-Esa1 interaction is important for the anti-silencing effects of 3-7-45 and the activation of replication origins in the silenced locus $H M L \alpha$}

Experiments with $\Delta$ eaf5 suggested a positive role for NuA4 in the anti-silencing effect of 3-7-45 and the activation of dormant origins in the silenced locus HML $\alpha$. However, deletions of nonessential subunits revealed a complex genetic interaction with sld3-6 (Figure 2B and Supplementary Figure S2B), and no interaction between Eaf5 and Sld3 could be detected in the $\mathrm{Y} 2 \mathrm{H}$ assay (Supplementary Figure S4A). Because an Esa1-Sld3 interaction was identified in the same assay (Figure 2 and Supplementary Figure S4A), we investigated the role of that interaction, rather than the NuA4 complex itself, in the role of 3-7-45 in antisilencing and DNA replication of dormant origins in the silenced locus. For this purpose, we isolated Sld3 mutants with diminished interaction with Esa1. Because Sld3 is essential for growth, we sought to isolate viable mutants for further analysis. Ultimately, we obtained three such mutants, sld $3^{\text {Esa1(-) }}-1,-2$, and -3 (Materials and Methods, Figure $4 \mathrm{~A})$. These three Sld3 ${ }^{\text {Esa1(-) }}$ mutants exhibited a significant reduction in the Esa1 interaction in the Y2H assay; in particular, Sld3 ${ }^{\text {Esa1(-) }}$-3 seemed to lose the interaction completely. Importantly, all mutants maintained interactions with other replication factors such as Sld7, Cdc45, Dpb11, Orc2, and Mcm6 at levels similar to those in the wild type (Figure 4A), indicating that they only diminished or lost the ability to interact with Esa1.

Mapping of mutated amino acids in Sld $3^{\mathrm{Esa} 1(-)}$ mutants revealed that all three mutants have amino acid substitutions in the Sld3/ Treslin homology domain, which is located in the middle of the Sld3 protein and conserved in Sld3 orthologs (Sanchez-Pulido et al. 2010) (Supplementary Figure S4B). Moreover, both Sld3 ${ }^{\text {Esa1(-) }}-1$ and -3 harbor an extra amino acid substitution in the C-terminal region, but these mutations seemed not to affect the Sld3 ${ }^{\text {Esa1(-) }}$ phenotype, as mutations in the Sld3/Treslin homology domain (N178F and N189Y in the Sld3 Esa1(-)-1 and P157T, T193S, and V264L in the Sld $3^{\text {Esa1(-) }}$-3) were sufficient for a diminished interaction with Esa1, and a single amino acid substitution in the C-terminal region alone (S459L in the Sld3 ${ }^{\operatorname{Esa1}(-)}-1$ and P623Q in the Sld3 ${ }^{\operatorname{Esa1}(-)}-3$ ) did not affect the Sld3-Esa1 interaction (data not shown). These findings imply that the Sld3/Treslin homology domain is important for the Sld3-Esa1 interaction.

To evaluate the importance of the Sld3-Esa1 interaction, we

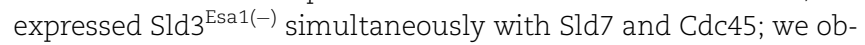
served that the anti-silencing effect was weaker in HML $\alpha:$ URA3 cells expressing Sld3 ${ }^{\text {Esa1(-) }}$ than in those expressing wild-type Sld3 (Figure 4B). This effect was roughly proportional to the decrease in the $\mathrm{Y} 2 \mathrm{H}$ signal, as this effect was stronger with the Sld3 $3^{\text {Esa1(-) }}-1$ and -3 than that with Sld3 $3^{\text {Esa1(-) }}-2$, which still shows very weak interaction with Esa1 in the $\mathrm{Y} 2 \mathrm{H}$ assay (Figure 4, $A$ and B). These observations indicate that the Sld3-Esa1 interaction is important for the anti-silencing effect caused by 3-7-45 expression. To observe the effect on the activity of dormant origins in $H M L \alpha$, we performed a plasmid loss assay. The loss rate of both the ARS301 and ARS301-320 plasmids was higher in the sld3 $3^{\text {Esa1(-) }}-3$ background than in the wild type, although the loss rate of the ARS1 plasmid was not changed.

We also isolated two viable Esa1 mutants with diminished interactions with Sld3, esa1 ${ }^{\text {Sld3(-) }}-1$ and -2 (Supplementary Figure $\mathrm{S} 4 \mathrm{C}$ ). Both mutants had multiple amino acid substitutions in the middle of the Esa1 protein, and at least one substitution was located in the MYST-type HAT domain. Of the 445 amino acids in Esa1, the N-terminal portion (aa 1-146) was dispensable for the Sld3 interaction, and most of the remaining part of the protein (aa 147-445) was a MYST-type HAT domain (aa 162-433) (Supplementary Figure S4A). Therefore, the MYST-type HAT domain is important for the interaction with Sld3. As in the case of sld3 ${ }^{E s a 1(-)}-3$, the loss rate of ARS301 and ARS301-320 plasmids was elevated in esa1 ${ }^{\text {Sld3(-) }}-2$ (Figure 4C). Collectively, these data indicate that the Sld3-Esa1 interaction has a positive effect on the activation of origins in the silenced locus.

\section{The Sld3-Esa1 interaction is important in the activation of not only dormant origins but also late origins on the chromosome}

As described above, 3-7-45 expression can promote the untimely activation of dormant origins in HML $\alpha$ in a chromosomal context. 
A

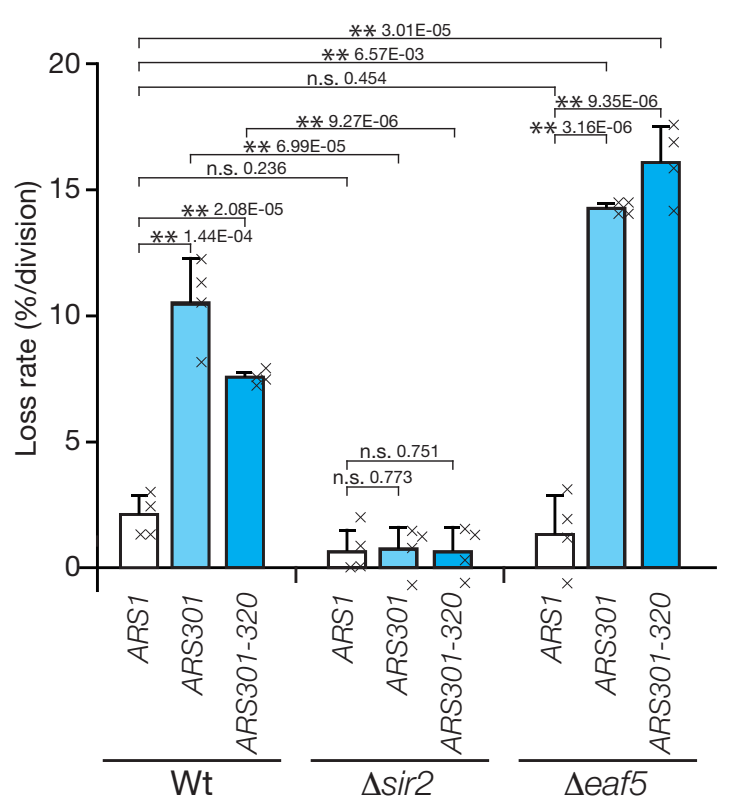

B Background: wt

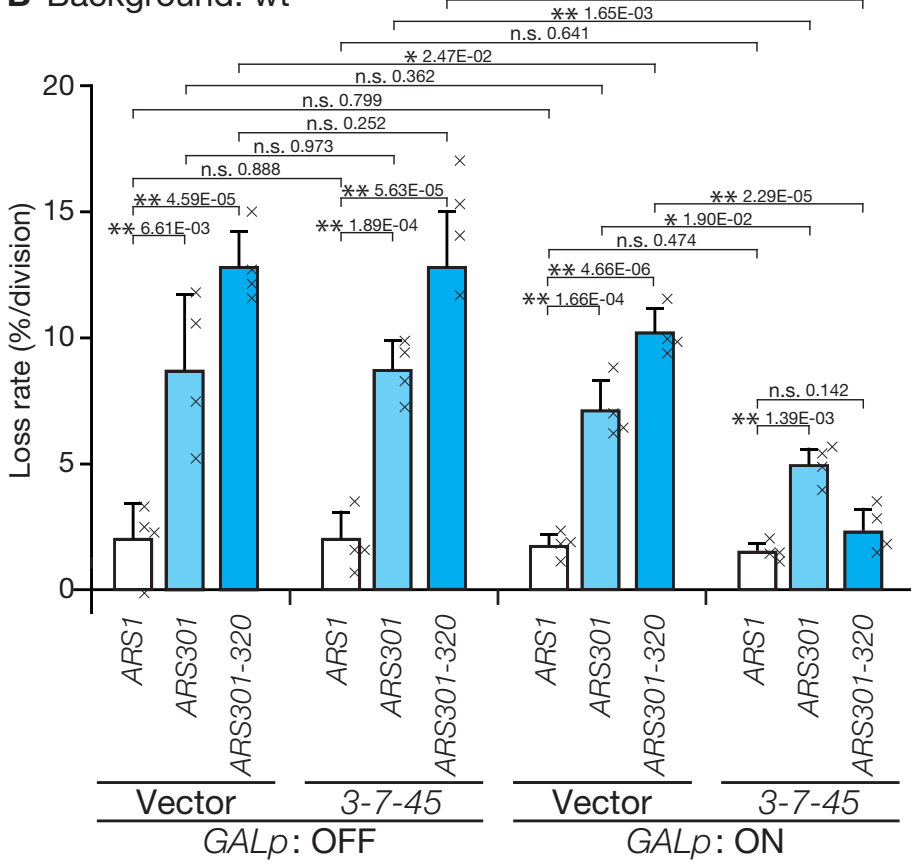

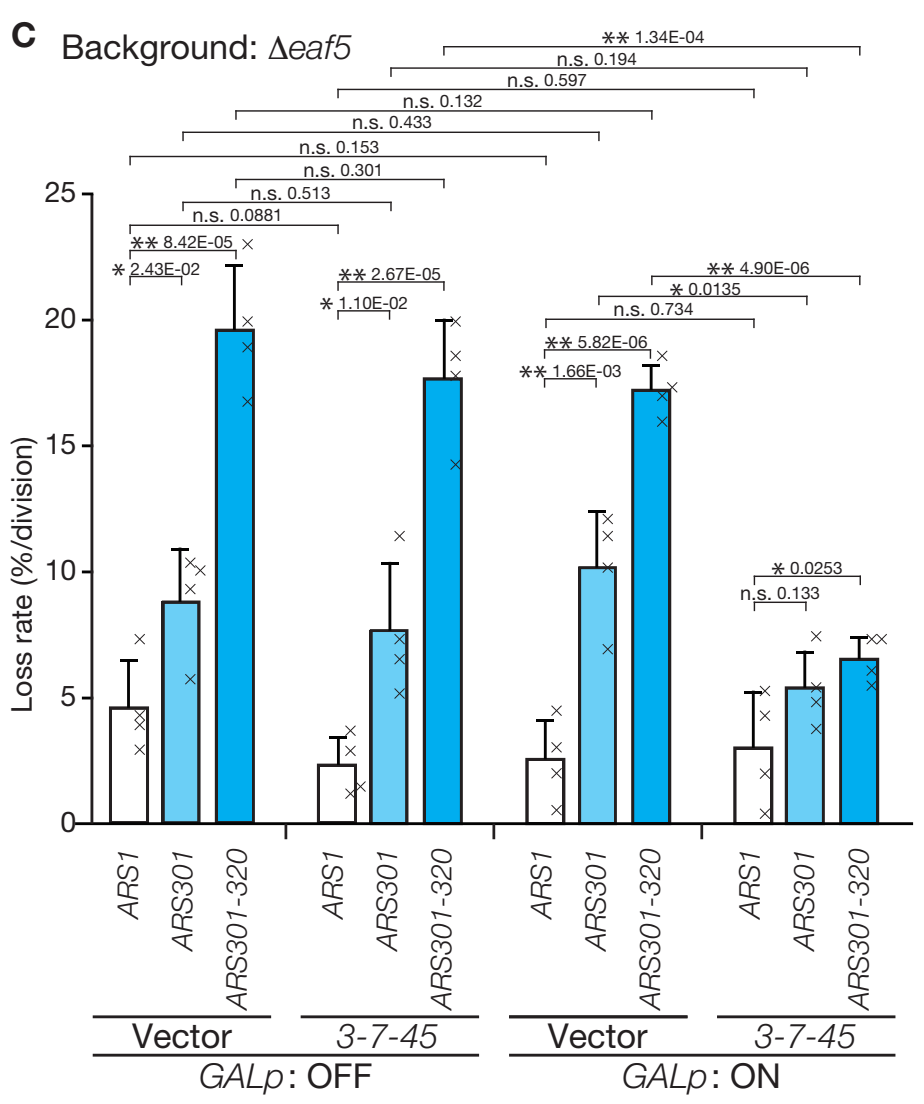

Figure 3. Plasmids harboring HML $\alpha$ origins replicate more efficiently when 3-7-45 is expressed, and less efficiently in the $\Delta$ eaf5 background. (A) Plasmid loss rates were measured using plasmids harboring the indicated ARSS (ARS1: pST1969; ARS301: pST1970; and ARS301-320: pST1971; see

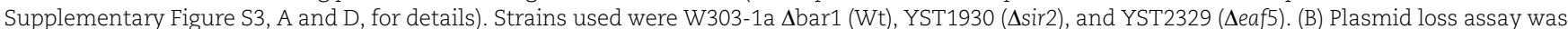
performed with host strains harboring either GALp vector (YST1038) or GALp-3-7-45 (YST1054). (C) Plasmid loss assay was performed with $\Delta e a f 5$ strains harboring either GALp vector (YST2482) or GALp-3-7-45 (YST2489). For each experiment, the average of four independent results is shown. Error bars: SD. Statistical significance in the differences was tested by the Student's t-test. ${ }^{* *} \mathrm{P}<0.01,{ }^{*} 0.01<\mathrm{P}<0.05$, and n.s. (not significant): P $>0.05$. Actual P-values are also shown. 
A
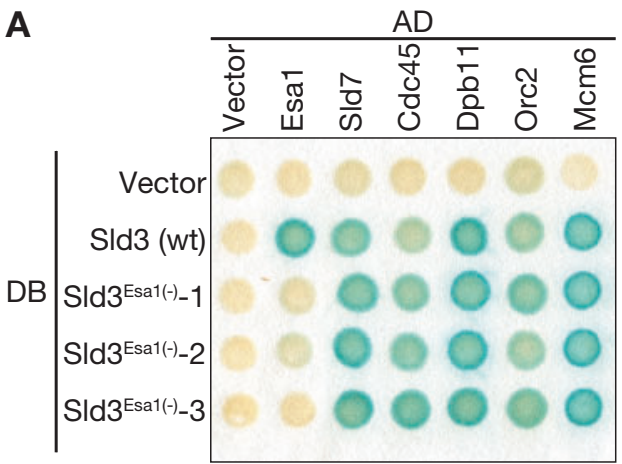

C

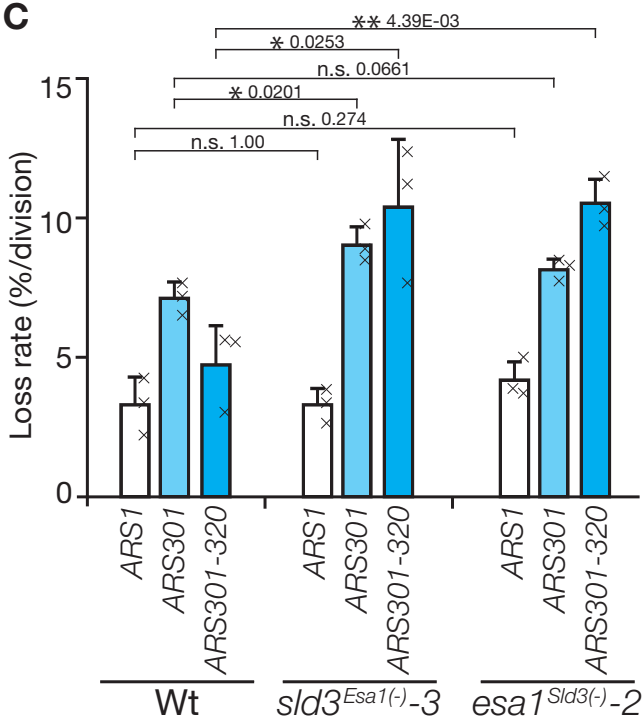

B

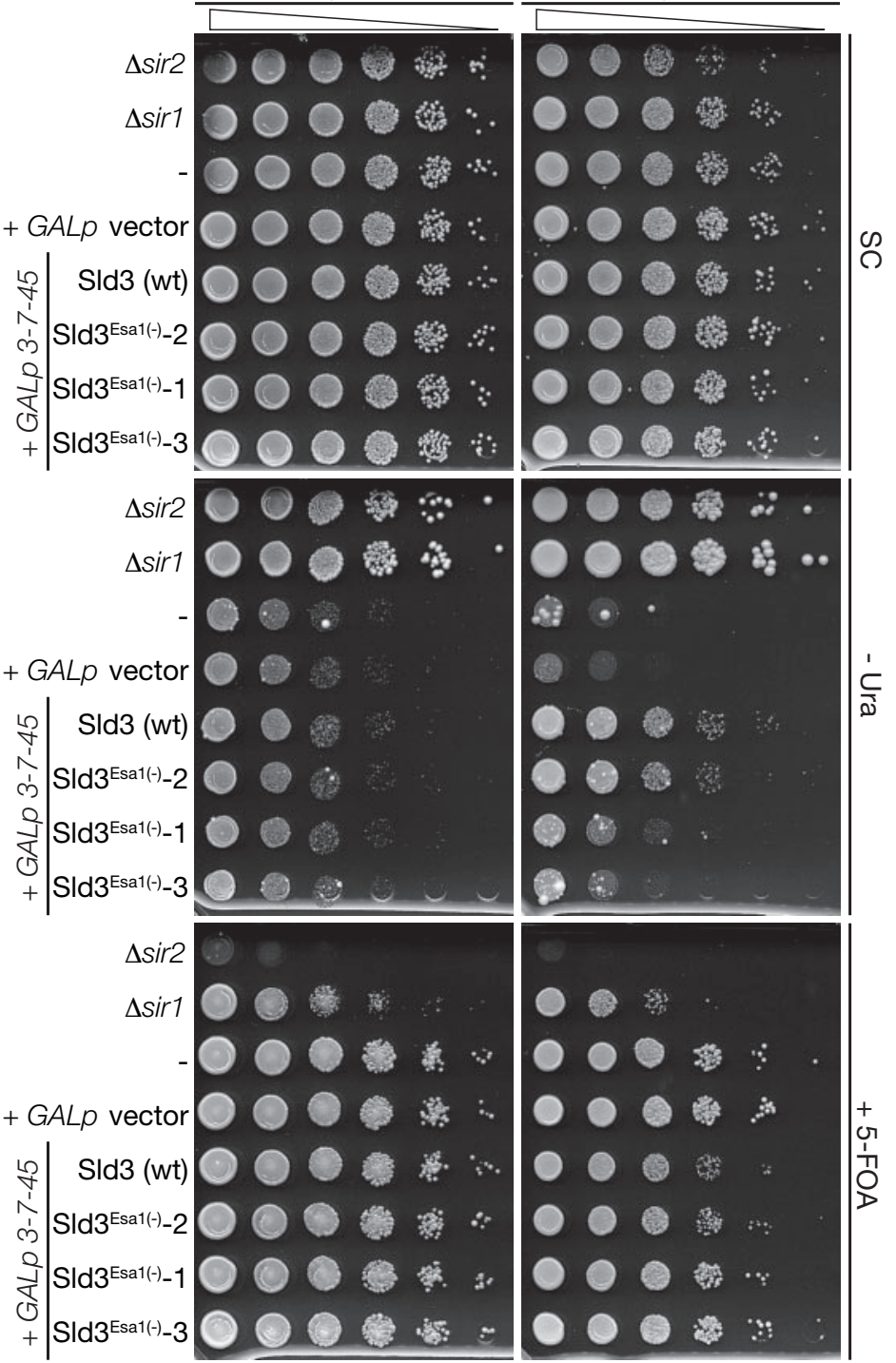

Figure 4. Mutants that diminish the Sld3-Esa1 interaction exhibit weaker anti-silencing effects and higher plasmid loss of HML $\alpha$ origins. (A) Isolation of Sld3 mutants with diminished interactions with Esa1. Y2H analysis was performed with the plasmids encoding the indicated proteins. (B) HML $\alpha:$ URA3 cells expressing Sld3 wild-type or Sld3 ${ }^{\text {Esa1(-) }}$ mutant proteins with Sld7 and Cdc45 were serially diluted, spotted, and grown on the indicated plates.

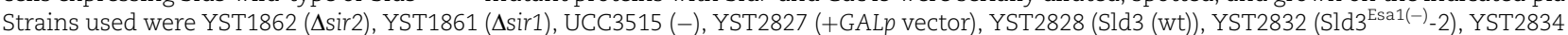

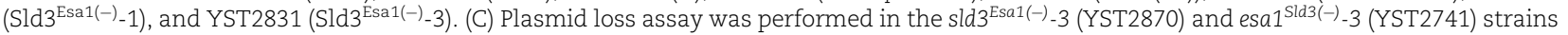
(Wt: YST2843). The average of three independent results is shown. Error bars: SD. Statistical significance in the differences was tested by the Student's t-test. ${ }^{* *} \mathrm{P}<0.01,{ }^{*} 0.01<\mathrm{P}<0.05$, and n.s. (not significant): $\mathrm{P}>0.05$. Actual $\mathrm{P}$-values are also shown.

Therefore, we further evaluated our $\operatorname{sld} 3^{\operatorname{Esa1}(-)}$ and $\operatorname{esa1}{ }^{\operatorname{Sld} 3(-)}$ mutants in the same situation. When Sld3 Esa1(-)-7-45 was expressed, although the activation of early origins such as ARS305 and ARS306 was not affected, the untimely activation of dormant origins in the HML $\alpha$ locus, ARS301 and ARS302-320, was diminished (Figure 5A). Surprisingly, in the both mutants, untimely activation of late replication origins ARS501 and ARS1410 was also diminished (Figure 5A). Similar results were also observed when 3-7-45 was expressed in the esa1 ${ }^{\text {Sld3(-) }}$ mutants, although the effect was not remarkable in the esa1 ${ }^{\text {Sld3(-) }}-1$ (Figure 5B). These data suggest that the Esa1-Sld3 interaction plays a role not only in the activation of dormant origins in the silenced locus but also in the activation of late origins.

Finally, we asked whether the Esa1-Sld3 interaction affects DNA replication under the normal condition by monitoring DNA replication in cells harboring the sld3 ${ }^{\operatorname{Esa1}(-)}-3$ or esa ${ }^{\text {Sld3(-) }}-2$ allele as the sole copy of the respective genes. Although overall progression of S-phase was largely unaffected when cells were synchronously released from G1 arrest, a very small delay might occur in late S-phase (Supplementary Figure S5, C and D). Therefore, to further clarify this point, we monitored DNA replication of the sld $3^{\text {Esa1 }(-)}-3$ and esa $1^{\text {Sld } 3(-)}-2$ cells in the medium containing a low dose of hydroxyurea (HU). Because high dose of HU (200 mM) blocks DNA replication by preventing the dNTP pool expansion (Koc et al. 2004) (for example, see Supplementary Figure $\mathrm{S} 5, \mathrm{~A}$ and $\mathrm{B})$, low dose of $\mathrm{HU}(25 \mathrm{mM})$ was employed. Under the mild condition, S-phase progression is allowed but slows down (Figure 5, C and D). Judging from the phosphorylation status of Orc6, a well-known substrate of S- and M-phase CDK (Liang and Stillman 1997; Tanaka et al. 2011), S-phase CDK is activated from 15 min after the release from G1 arrest and DNA replication seemed to initiate at the same time in all strains (Figure 5, C and D). However, the progression of S-phase in later time points (45-105 min) in sld3 ${ }^{\text {Esa1(-) }}-3$ and esa1 ${ }^{\text {Sld3(-) }}$-2 cells were slower 


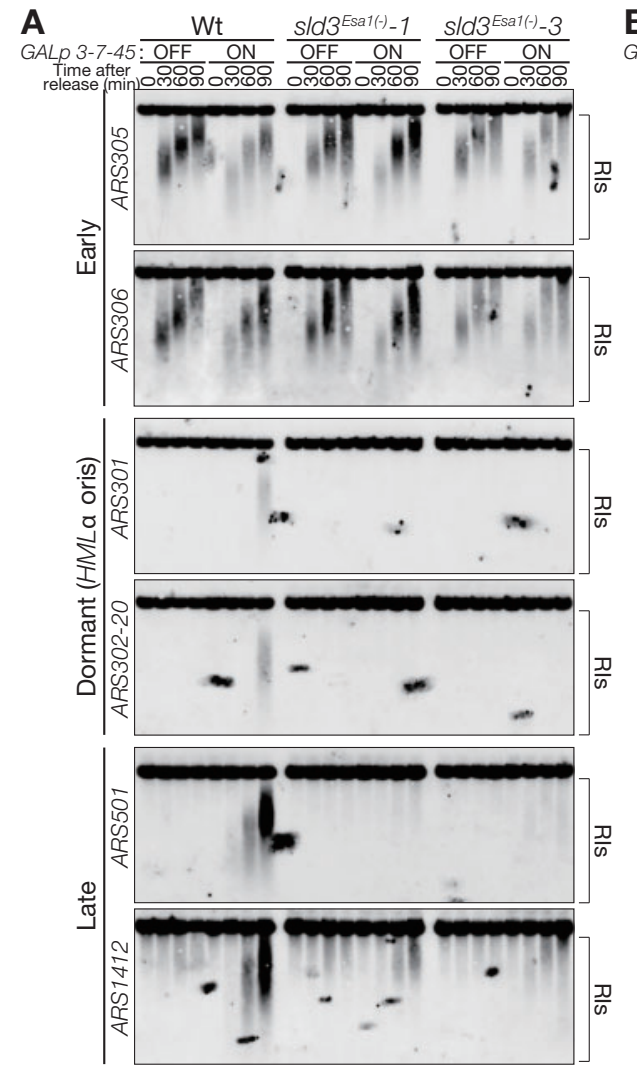

C

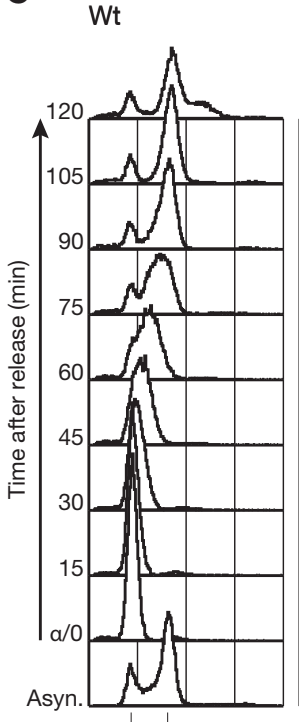

$1 \mathrm{C} 2 \mathrm{C}$

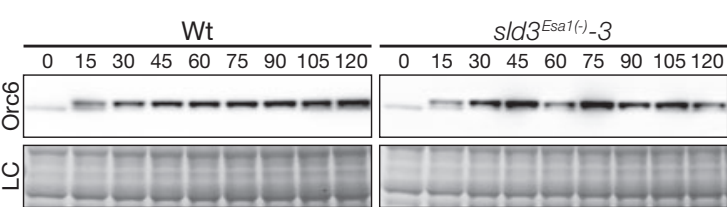

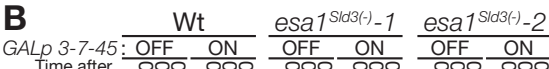
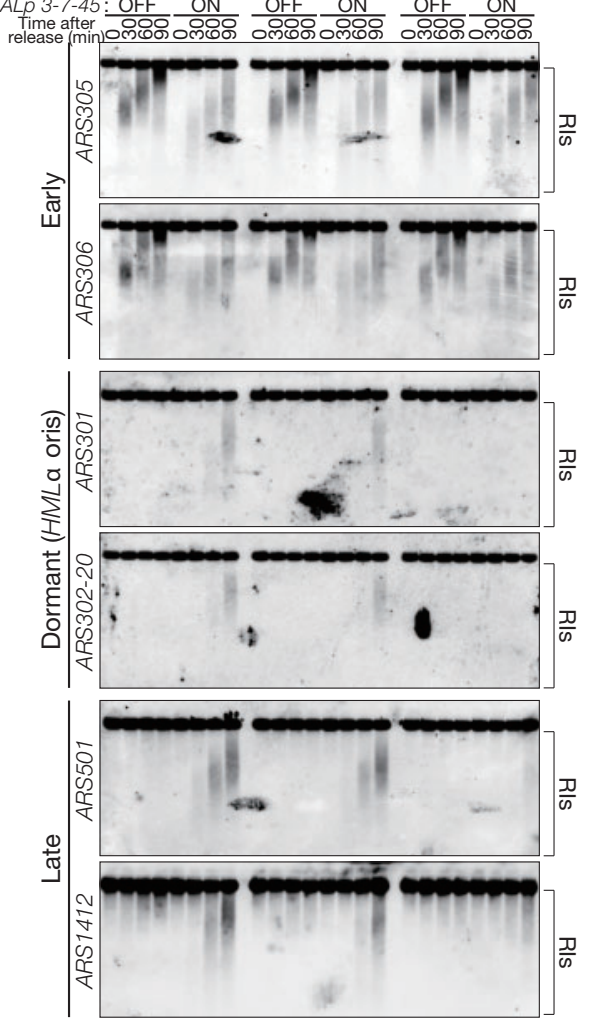

D wt

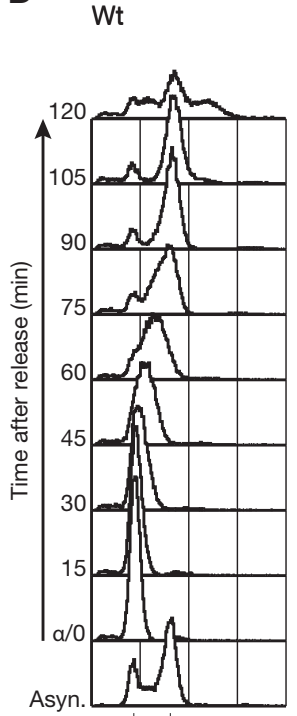

1C $2 \mathrm{C}$

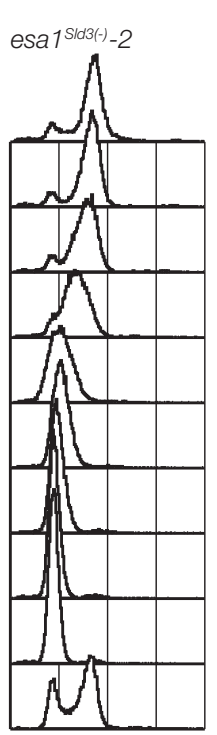

$1 \mathrm{l} \quad 2 \mathrm{C}$
Overlay
(Wt_esa 1 IId(-)-2)

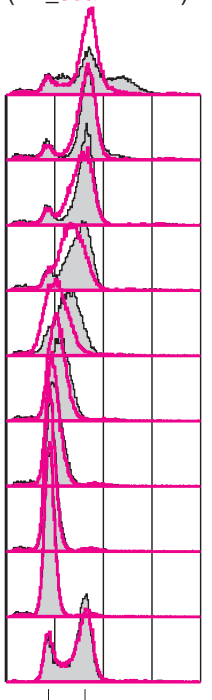

$1 \mathrm{C} 2 \mathrm{C}$

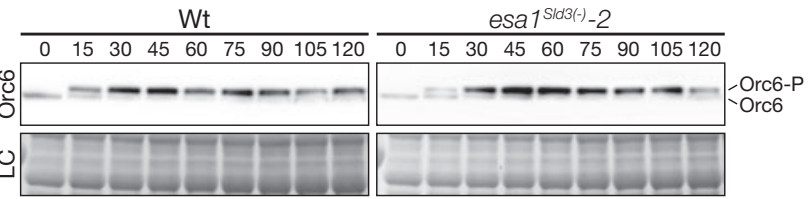

Figure 5. Untimely activation of origins is diminished in mutants that diminish the Sld3-Esa1 interaction. (A) Wild-type (YST2895), sld3 Esa1(-) -1 (YST2898), and sld3 ${ }^{\text {Esa1(-) }}-3$ (YST2903) cells in which 3-7-45 was expressed were arrested in G1 with $\alpha$ factor, and the culture was split into two. 3-7-45 was induced in one half but not in the other; the cultures were then released into the media containing HU, and samples were collected at the indicated times. DNA was extracted from the samples and analyzed using alkaline gels. Replication intermediates (RIs) were detected using ARS-specific probes. Please note that in sld3 ${ }^{\text {Esa1(-) }}$ cells, the corresponding Sld3 ${ }^{\text {Esa1(-) }}$ protein was expressed rather than wild-type Sld3. Profiles of DNA contents of samples are shown in Supplementary Figure S5. (B) RIs from various ARSs in wild-type (YST2749), esa1 ${ }^{\text {sld3(-) }}-1$ (YST2751), and esa1 ${ }^{\text {Sld3(-) }}$-2 (YST2752) cells in which 3-7-45 was expressed were analyzed as in (A). (C) Wild-type (YST2843) and sld3 ${ }^{\text {Esa1 (-) }}$-3 (YST2870) cells were arrested in G1 with $\alpha$ factor and released in fresh YPAD medium containing $25 \mathrm{mM}$ HU. Samples were collected every $15 \mathrm{~min}$ after release and analyzed by flow cytometry (top) and western blotting (bottom): Orc6 proteins were detected with SB49 monoclonal antibody (Liang and Stillman 1997); LC (loading control) shows the corresponding region of the membrane stained with Ponceau-S. (D) Wild-type (W303-1a $\Delta$ bar1) and esa1 ${ }^{\text {Sld3(-) }-2 ~(Y S T 2741) ~ c e l l s ~ w e r e ~ a n a l y z e d ~ a s ~ i n ~(C) . ~}$ 
than that of wild-type cells (Figure 5, C and D). These suggest that the firing of early origins was unaffected, but that of late origins was affected, in sld $3^{\operatorname{Esa1}(-)}-3$ and esa $1^{\text {Sld3(-) }}-2$ cells.

\section{Discussion}

In this study, we showed that 3-7-45 expression affects not only the firing of dormant origins in the silenced locus HML $\alpha$ but also the silencing status of the locus. These effects depended on the interaction of Sld3 and Esa1. The Sld3-Esa1 interaction also affected the activation of late origins. Therefore, our data reveal a novel mechanism regulating the firing of replication origins.

\section{The anti-silencing effect caused by 3-7-45 expression is transient}

Chromatin silencing is maintained over generations. In this study, by monitoring the activity of a URA3 gene inserted into the HML $\alpha$ locus, we found that 3-7-45 expression counteracted the silencing of the locus. This effect was strengthened in the $\Delta$ swe1 mutant, which has a longer G1 phase than the wild type, and the opposite effect was observed in the $\Delta$ mih1 mutant, which has a shorter G1 phase than the wild type. 3-7-45 transiently associates with the Mcm2-7 complex on licensed origins when they fire, and origins are licensed in the G1 phase, implying that the anti-silencing effect of $3-7-45$ is related to their association to licensed replication origins.

On 5-FOA plates, colonies expressing 3-7-45 were smaller than those expressing vector control, indicating that the level of Ura3 was higher in the 3-7-45 cells; by contrast, the number of colonies formed was largely unaffected (Figure 1D). Therefore, the anti-silencing effect of 3-7-45 seems to be transient, rather than representing a switch in status. When Sld3 ${ }^{\text {Esa1(-) }}$ mutants were expressed, colony size increased, but once again the number of colonies was not affected (Figure 4B, +5-FOA panel). Therefore, we propose the following model: when 3-7-45 is associated with licensed origins, local chromatin structure is transiently changed via the function of Esa1. Although our data cannot strictly exclude the possibility that Esa1 locates silenced origins prior to the association of Sld3, it would be difficult to explain the transient effect of 3-7-45 expression in such a situation.

Interestingly, in the in vitro replication assay with chromatinized template, Esa1 accumulated on template chromatin DNA when S-phase extract was added. This requires $\mathrm{Mcm} 2-7$ loading and subsequent DDK treatment (Kurat et al. 2017). Because Sld3 associates with the Mcm2-7 complex at licensed origins in a DDKdependent manner (Heller et al. 2011; Tanaka et al. 2011; Deegan et al. 2016), these in vitro data are consistent with our model.

In chromatin immunoprecipitation (ChIP) assays, we tried to detect association with Esa1 or a reduction in the level of the silencer protein Sir2 at the HMLa locus following 3-7-45 expression, but we detected no changes (data not shown). Because Sld3 transiently associates with licensed origins during the firing reaction, the association of Esa1 with silenced origins might occur in a very short window and ChIP analysis might not be sensitive enough to detect such transient changes.

Genome silencing is stably maintained throughout the cell cycle and over generations. Hence, our finding that temporary anti-silencing, or fluctuation of silencing, can occur when an origin fires reveals a novel mode of silencing regulation.

\section{Target and the role of Esa1 in the firing reaction}

Esa1, a lysine acetyltransferase and the catalytic subunit of the NuA4 complex, acetylates four conserved lysines in the histone H4 N-terminal tail at positions 5, 8, 12, and 16 (Dhar et al. 2017).
Therefore, transient recruitment of Esa1 by Sld3 might transiently change the modification levels of local proteins. Using ChIP with the specific antibodies against H4K5Ac, H4K8Ac, H4K12Ac, and H4K16Ac raised by the Kimura group (Hayashi-Takanaka et al. 2015), we tried to detect changes in these modifications in 3-7-45 expressing cells. However, as in the case of the Esa1-ChIP, we could not detect significant changes, probably because of technical limitations. Further analysis that is aimed at identifying Esa1 targets, including non-histones, will be necessary to understand the precise role of Esa1 in the firing reaction. The aforementioned in vitro replication assay (Kurat et al. 2017) would be very useful for elucidating the function of Esa1 in the firing reaction.

\section{Is the full NuA4 complex required for anti- silencing and untimely activation of $H M L \alpha$ origins caused by 3-7-45 expression?}

Budding yeast NuA4 consists of 13 unique subunits, including Esa1 (Allard et al. 1999). We tested the genetic interactions between NuA4 and Sld3 by combining deletions of non-essential subunits of NuA4 ( $\Delta$ eaf3, $\Delta$ eaf5, $\Delta$ eaf6, $\Delta$ eaf7, and $\Delta y a f 9)$ with sld3ts alleles. Although we detected genetic interactions (Figure 2 and Supplementary Figure S2), the strengths and directions of these interactions were complex. Although this might be partly due to differences between sld3-5 and sld3-6 (see below), the structure of the NuA4 complex might also affect the phenotype. For example, the 13 subunits of NuA4 can be separated into subcomplexes, one of which is the TINTIN triad consisting of Eaf3, Eaf5, and Eaf7 (Cheng and Cote 2014; Rossetto et al. 2014). Deaf3 and $\Delta$ eaf5 exacerbated the growth defects of sld3-6 to different extents, whereas seaf7 suppressed the growth defects (Figure $2 \mathrm{~B}$ and Supplementary Figure S2B). By contrast, in sld3-5, $\Delta$ eaf5 and $\Delta$ eaf7 weakly exacerbated the growth defects, whereas $\Delta$ eaf3 did not (Supplementary Figure S2C). Moreover, although both $\Delta$ eaf5 and seaf6 exacerbated the phenotypes of sld3-5 and sld3-6, neither Eaf5 nor Eaf6 interacted with Sld3 in the Y2H assay. Together, these findings suggest the existence of different role(s) for NuA4 subunits or other subcomplexes.

\section{Conservation of the Esa1-Sld3 interaction and its impact on genome duplication}

We isolated Sld3 ${ }^{\text {Esa1(-) }}$ and Esa1 ${ }^{\text {Sld3(-) }}$ mutants in which the Sld3Esa1 interaction was diminished. All mutants had at least one amino acid substitution in their conserved domains: the Sld3/ Treslin homology domain in Sld3 and the MYST-type HAT domain in Esa1. The Sld3/Treslin homology domain is a conserved Cdc45-binding domain that contains 12 helices (Itou et al. 2014). All Sld3 ${ }^{\text {Esa1(-) }}$ mutants had an amino acid substitution in the helix 2 (aa 176-195). The helix 2 contains basic amino acids that are conserved and form a basic patch on the surface of the Sld3/ Treslin homology domain with basic amino acids in the helix 12. This basic patch does not seem to be the Cdc45 association domain because the Cdc45 association was unaffected in the KR2E mutation of the Sld3/Treslin homology domain, in which five basic amino acids in the helix 2 and 12 were replaced by glutamic acid (Itou et al. 2014). Therefore, helix 2 in the Sld3/Treslin homology domain might be the conserved Esa1 interaction domain.

We used two temperature-sensitive alleles of sld3, sld3-5 and sld3-6 (Kamimura et al. 2001), to analyze the interaction between Sld3 and NuA4. A genetic interaction was observed in both mutants; however, the interaction in sld3-5 was much weaker than that in sld3-6 (Figure 2 and Supplementary Figure S2). The amino acid substitutions in Sld3-5 are G125D and F170S, and the substitution in Sld3-6 is E63G (Kamimura et al. 2001). F170 is 
located in helix 2 in the Sld3/Treslin homology domain. Therefore, if helix 2 is responsible for the association with Esa1, it could explain the difference in the genetic interactions between NuA4 and sld3-5 and sld3-6. Notably in this regard, the KR2E mutant does not support cell growth (Itou et al. 2014), whereas our Sld3 ${ }^{\text {Esa1(-) }}$ mutants did. Therefore, further investigations are necessary to understand the exact role of the basic patch in the Sld3/Treslin homology domain in the Sld3-Esa1 interaction.

Although the mutation sites of our Esa ${ }^{\text {Sld3(-) }}$ mutants were dispersed throughout the protein (Supplementary Figure S2D), both Esa1 ${ }^{\text {Sld3(-) }}$ mutants have amino acid substitution(s) in the conserved MYST-type HAT domain. Given that both Sld3 $3^{\text {Esa1(-) }}$ and Esa1 ${ }^{\text {Sld } 3(-)}$ mutants had amino acid substitutions in their conserved domains, the Sld3-Esa1 interaction might be conserved through evolution.

In this study, we showed that untimely firing of dormant origins and late origins, which is induced by 3-7-45 expression, was diminished in Sld3 ${ }^{\operatorname{Esa1}(-)}$ and Esa1 ${ }^{\text {Sld3(-) }}$ (Figure 5). When DNA replication was monitored in cells harboring the $\operatorname{sld} 3^{\text {Esa1(-) }}-3$ or esa1 ${ }^{\text {Sld } 3(-)}-2$ allele as the sole copy of the respective genes, overall progression of S-phase was largely unaffected, although a very small delay might occur in late S-phase (Supplementary Figure S5, C and D). Similar phenotype was observed with the degron allele of ESA1, esa1-td (Early et al. 2004). Dormant origins have the potential to fire but under normal conditions do not fire because replication forks pass through before they can (Bartel and Fields 1995; Santocanale et al. 1999). Late origins fire under normal conditions; however, if firing is slightly delayed, a replication fork could pass through before firing. We speculate that such a situation is arising in our sld $3^{\text {Esa1(-) }}$ and esa1 $1^{\text {Sld3(-) }}$ mutants and esa1-td; therefore, the overall progression of S-phase in these mutants was not strongly affected in our sld $3^{\text {Esa1(-) }}$ and esa1 ${ }^{\text {Sld3(-) }}$ mutants (Figure 5, C and D). In the budding yeast S. cerevisiae, only a small amount of the genome is silenced; by contrast, in mammals, huge sections of the genome are silenced. Because the Sld3-Esa1 interaction may be conserved, future studies should seek to elucidate the role of Sld3-Esa1 in other eukaryotes.

\section{Acknowledgments}

We are deeply grateful to M. Miyazawa-Onami and A. Hosoe for their technical assistance, to H. Kimura for antibodies against acetylated histones, and to B. Stillman for the SB49 antibody. We also thank H. Araki, M. Yagura, and Y. Tanaka for help and discussion.

S.T. is responsible for all aspects of the study.

\section{Funding}

This work was supported by grants from the Uehara Memorial Foundation; the Institute for Fermentation, Osaka; the Ministry of Education, Culture, Sports, Science and Technology; and the Japan Society for the Promotion of Science (Grant No. 25131721).

Conflicts of interest: None declared.

\section{Literature cited}

Aizawa M, Sugimoto N, Watanabe S, Yoshida K, Fujita M. 2016. Nucleosome assembly and disassembly activity of GRWD1, a novel Cdt1-binding protein that promotes pre-replication complex formation. Biochim Biophys Acta. 1863:2739-2748.

Allard S, Utley RT, Savard J, Clarke A, Grant P, et al. 1999. NuA4, an essential transcription adaptor/histone H4 acetyltransferase complex containing Esa1p and the ATM-related cofactor Tra1p. EMBO J. 18:5108-5119.

Bartel PL, Fields S. 1995. Analyzing protein-protein interactions using two-hybrid system. Methods Enzymol. 254:241-263.

Berbenetz NM, Nislow C, Brown GW. 2010. Diversity of eukaryotic DNA replication origins revealed by genome-wide analysis of chromatin structure. PLoS Genet. 6:e1001092.

Boeke JD, Trueheart J, Natsoulis G, Fink GR. 1987. 5-Fluoroorotic acid as a selective agent in yeast molecular genetics. Methods Enzymol. 154:164-175.

Booher RN, Deshaies RJ, Kirschner MW. 1993. Properties of Saccharomyces cerevisiae wee1 and its differential regulation of p34CDC28 in response to G1 and G2 cyclins. EMBO J. 12: 3417-3426.

Bousset K, Diffley JF. 1998. The Cdc7 protein kinase is required for origin firing during S phase. Genes Dev. 12:480-490.

Brustel J, Kirstein N, Izard F, Grimaud C, Prorok P, et al. 2017. Histone $\mathrm{H} 4 \mathrm{~K} 20$ tri-methylation at late-firing origins ensures timely heterochromatin replication. EMBO J. 36:2726-2741.

Chadha GS, Blow JJ. 2010. Histone acetylation by HBO1 tightens replication licensing. Mol Cell. 37:5-6.

Cheng X, Cote J. 2014. A new companion of elongating RNA Polymerase II: TINTIN, an independent sub-module of NuA4/TIP60 for nucleosome transactions. Transcription. 5:e995571.

Clarke AS, Lowell JE, Jacobson SJ, Pillus L. 1999. Esa1p is an essential histone acetyltransferase required for cell cycle progression. Mol Cell Biol. 19:2515-2526.

Coster G, Diffley JFX. 2017. Bidirectional eukaryotic DNA replication is established by quasi-symmetrical helicase loading. Science. 357:314-318.

Deegan TD, Yeeles JT, Diffley JF. 2016. Phosphopeptide binding by Sld3 links Dbf4-dependent kinase to MCM replicative helicase activation. EMBO J. 35:961-973.

Devbhandari S, Jiang J, Kumar C, Whitehouse I, Remus D. 2017. Chromatin constrains the initiation and elongation of DNA replication. Mol Cell. 65:131-141.

Dhar S, Gursoy-Yuzugullu O, Parasuram R, Price BD. 2017. The tale of a tail: histone $\mathrm{H} 4$ acetylation and the repair of DNA breaks. Phil Trans R Soc B: Biol Sci. 372: 20160284.

Douglas ME, Ali FA, Costa A, Diffley JFX. 2018. The mechanism of eukaryotic CMG helicase activation. Nature. 555:265-268.

Early A, Drury LS, Diffley JF. 2004. Mechanisms involved in regulating DNA replication origins during the cell cycle and in response to DNA damage. Philos Trans R Soc Lond B. 359:31-38.

Eaton ML, Galani K, Kang S, Bell SP, MacAlpine DM. 2010. Conserved nucleosome positioning defines replication origins. Genes Dev. 24:748-753.

Evrin C, Clarke P, Zech J, Lurz R, Sun J, et al. 2009. A double-hexameric MCM2-7 complex is loaded onto origin DNA during licensing of eukaryotic DNA replication. Proc Natl Acad Sci USA. 106:20240-20245.

Foltman M, Evrin C, De Piccoli G, Jones RC, Edmondson RD, et al. 2013. Eukaryotic replisome components cooperate to process histones during chromosome replication. Cell Rep. 3:892-904.

Gross DS. 2001. Sir proteins as transcriptional silencers. Trends Biochem Sci. 26:685-686.

Hayashi-Takanaka Y, Maehara K, Harada A, Umehara T, Yokoyama S, et al. 2015. Distribution of histone H4 modifications as revealed 
by a panel of specific monoclonal antibodies. Chromosome Res. 23:753-766.

Heller RC, Kang S, Lam WM, Chen S, Chan CS, et al. 2011. Eukaryotic origin-dependent DNA replication in vitro reveals sequential action of DDK and S-CDK kinases. Cell. 146:80-91.

Itou H, Muramatsu S, Shirakihara Y, Araki H. 2014. Crystal structure of the homology domain of the eukaryotic DNA replication proteins Sld3/Treslin. Structure. 22:1341-1347.

Ivy JM, Klar AJ, Hicks JB. 1986. Cloning and characterization of four SIR genes of Saccharomyces cerevisiae. Mol Cell Biol. 6:688-702.

Kamimura Y, Tak YS, Sugino A, Araki H. 2001. Sld3, which interacts with Cdc45 (Sld4), functions for chromosomal DNA replication in Saccharomyces cerevisiae. EMBO J. 20:2097-2107.

Kanke M, Kodama Y, Takahashi TS, Nakagawa T, Masukata H. 2012. Mcm10 plays an essential role in origin DNA unwinding after loading of the CMG components. EMBO J. 31:2182-2194.

Koc A, Wheeler LJ, Mathews CK, Merrill GF. 2004. Hydroxyurea arrests DNA replication by a mechanism that preserves basal dNTP pools. J Biol Chem. 279:223-230.

Kurat CF, Yeeles JT, Patel H, Early A, Diffley JF. 2017. Chromatin controls DNA replication origin selection, lagging-strand synthesis, and replication fork rates. Mol Cell. 65:117-130.

Liang C, Stillman B. 1997. Persistent initiation of DNA replication and chromatin-bound MCM proteins during the cell cycle in cdc6 mutants. Genes Dev. 11:3375-3386.

Looke M, Maloney MF, Bell SP. 2017. Mcm10 regulates DNA replication elongation by stimulating the CMG replicative helicase. Genes Dev. 31:291-305.

Miller TCR, Locke J, Greiwe JF, Diffley JFX, Costa A. 2019. Mechanism of head-to-head MCM double-hexamer formation revealed by cryo-EM. Nature. 575:704-710.

Miyazawa-Onami M, Araki H, Tanaka S. 2017. Pre-initiation complex assembly functions as a molecular switch that splits the Mcm2-7 double hexamer. EMBO Rep. 18:1752-1761.

Muramatsu S, Hirai K, Tak YS, Kamimura Y, Araki H. 2010. CDK-dependent complex formation between replication proteins Dpb11, Sld2, Pol (epsilon), and GINS in budding yeast. Genes Dev. 24:602-612.

Pillus L, Rine J. 1989. Epigenetic inheritance of transcriptional states in S. cerevisiae. Cell. 59:637-647.

Pillus L, Rine J. 2004. SIR1 and the origin of epigenetic states in Saccharomyces cerevisiae. Cold Spring Harb Symp Quant Biol. 69:259-265.

Remus D, Beuron F, Tolun G, Griffith JD, Morris EP, et al. 2009. Concerted loading of Mcm2-7 double hexamers around DNA during DNA replication origin licensing. Cell. 139:719-730.

Rhind N, Gilbert DM. 2013. DNA replication timing. Cold Spring Harb Perspect Biol. 5:a010132-a010132.

Rine J, Herskowitz I. 1987. Four genes responsible for a position effect on expression from HML and HMR in Saccharomyces cerevisiae. Genetics. 116:9-22.

Rossetto D, Cramet M, Wang AY, Steunou AL, Lacoste N, et al. 2014. Eaf5/7/3 form a functionally independent NuA4 submodule linked to RNA polymerase II-coupled nucleosome recycling. EMBO J. 33:1397-1415.

Russell P, Moreno S, Reed SI. 1989. Conservation of mitotic controls in fission and budding yeasts. Cell. 57:295-303.

Sanchez-Pulido L, Diffley JF, Ponting CP. 2010. Homology explains the functional similarities of Treslin/Ticrr and Sld3. Curr Biol. 20: R509-510.
Santocanale C, Diffley JF. 1996. ORC- and Cdc6-dependent complexes at active and inactive chromosomal replication origins in Saccharomyces cerevisiae. EMBO J. 15:6671-6679.

Santocanale C, Sharma K, Diffley JF. 1999. Activation of dormant origins of DNA replication in budding yeast. Genes Dev. 13:2360-2364.

Singer MS, Gottschling DE. 1994. TLC1: template RNA component of Saccharomyces cerevisiae telomerase. Science. 266:404-409.

Sugimoto N, Maehara K, Yoshida K, Yasukouchi S, Osano S, et al. 2015. Cdt1-binding protein GRWD1 is a novel histone-binding protein that facilitates MCM loading through its influence on chromatin architecture. Nucleic Acids Res. 43:5898-5911.

Sugimoto N, Yugawa T, Iizuka M, Kiyono T, Fujita M. 2011. Chromatin remodeler sucrose nonfermenting 2 homolog (SNF2H) is recruited onto DNA replication origins through interaction with Cdc10 protein-dependent transcript 1 (Cdt1) and promotes pre-replication complex formation. J Biol Chem. 286:39200-39210.

Tan BC, Chien CT, Hirose S, Lee SC. 2006. Functional cooperation between FACT and MCM helicase facilitates initiation of chromatin DNA replication. EMBO J. 25:3975-3985.

Tanaka S. 2019. An efficient method for the isolation of interaction-null/impaired mutants using the yeast two-hybrid technique. Genes Cells. 24:781-788.

Tanaka S, Araki H. 2013. Helicase activation and establishment of replication forks at chromosomal origins of replication. Cold Spring Harb Perspect Biol. 5:a010371.

Tanaka S, Diffley JF. 2002a. Deregulated G1-cyclin expression induces genomic instability by preventing efficient pre-RC formation. Genes Dev. 16:2639-2649.

Tanaka S, Diffley JF. 2002b. Interdependent nuclear accumulation of budding yeast Cdt1 and Mcm2-7 during G1 phase. Nat Cell Biol. 4: 198-207.

Tanaka S, Komeda Y, Umemori T, Kubota Y, Takisawa H, et al. 2013. Efficient initiation of DNA replication in eukaryotes requires Dpb11/TopBP1-GINS interaction. Mol Cell Biol. 33:2614-2622.

Tanaka S, Nakato R, Katou Y, Shirahige K, Araki H. 2011. Origin association of sld3, sld7, and cdc45 proteins is a key step for determination of origin-firing timing. Curr Biol. 21:2055-2063.

Tanaka S, Umemori T, Hirai K, Muramatsu S, Kamimura Y, et al. 2007. CDK-dependent phosphorylation of Sld2 and Sld3 initiates DNA replication in budding yeast. Nature. 445:328-332.

Ticau S, Friedman LJ, Champasa K, Correa IR, Jr.,Gelles J, et al. 2017. Mechanism and timing of Mcm2-7 ring closure during DNA replication origin licensing. Nat Struct Mol Biol. 24:309-315.

Ticau S, Friedman LJ, Ivica NA, Gelles J, Bell SP. 2015. Single-molecule studies of origin licensing reveal mechanisms ensuring bidirectional helicase loading. Cell. 161:513-525.

van Deursen F, Sengupta S, De Piccoli G, Sanchez-Diaz A, Labib K. 2012. Mcm10 associates with the loaded DNA helicase at replication origins and defines a novel step in its activation. EMBO J. 31:2195-2206.

Vujcic M, Miller CA, Kowalski D. 1999. Activation of silent replication origins at autonomously replicating sequence elements near the HML locus in budding yeast. Mol Cell Biol. 19:6098-6109.

Watase G, Takisawa H, Kanemaki MT. 2012. Mcm10 Plays a Role in Functioning of the Eukaryotic Replicative DNA Helicase, Cdc45-Mcm-GINS. Curr Biol. 22:343-349.

Zegerman P, Diffley JF. 2007. Phosphorylation of Sld2 and Sld3 by cyclin-dependent kinases promotes DNA replication in budding yeast. Nature. 445:281-285. 